\title{
Early Career Award for Excellence in Teaching and Innovation
}

Published online: 17 December 2019

(C) International Association of Medical Science Educators 2019

This annual award honors an IAMSE member who has made significant innovations to the field in the short time they have focused their careers toward enhancing teaching, learning, and assessment. Candidates for this award will be Assistant Professor or equivalent rank, or have demonstrated less than 10 years of educational scholarship. An award recipient will have a record of excellence in teaching at his/her institution and possess a record of engagement within IAMSE. It is recognized that, while the successful nominee will have a proven track record of innovating and helping advance the art of teaching, she/he may not yet have achieved significant accomplishments in scholarship. Nominations of members who have been active teachers (e.g., presenters and facilitators) at the annual IAMSE meetings are particularly encouraged. IAMSE members may self-nominate or be nominated by another IAMSE member. The Educational Scholarship Committee reviews all nominations and supporting documentation based on established criteria and selects finalists. Final selection of each award recipient rests with the Awards Committee.

\section{Award Winner - Kelly M. Quesnelle, PhD}

Assistant Professor of Biomedical Sciences, Western Michigan University, USA

Kelly M. Quesnelle, PhD is an Assistant Professor of Biomedical Sciences at Western Michigan University Homer Stryker M.D. School of Medicine (WMed). Dr. Quesnelle earned her BS from the University of Michigan and her $\mathrm{PhD}$ from the University of Pittsburgh School of Medicine (Pitt). She completed a postdoctoral fellowship in the Vascular Medicine Institute at Pitt, including training at the US Food and Drug Administration. In 2014, Dr. Quesnelle joined WMed as a founding faculty member where she currently serves as the pharmacology discipline director and the basic science director of the hematology and oncology course. She also currently serves as the IRB chairperson and a steering committee member for Women in Medicine and Science. Dr. Quesnelle's educational research focuses on assessment outcomes and innovation in the undergraduate medical classroom. She has published work in medical education journals and presented at IAMSE and other meetings. In 2018, Dr. Quesnelle was awarded a Medical Education Research \& Innovation Challenge Grant from ScholarRx@. Dr. Quesnelle has been an active member of IAMSE since 2015, and she is thankful to the many members of IAMSE at her home institution and around the globe who have helped mentor her career as a medical educator.

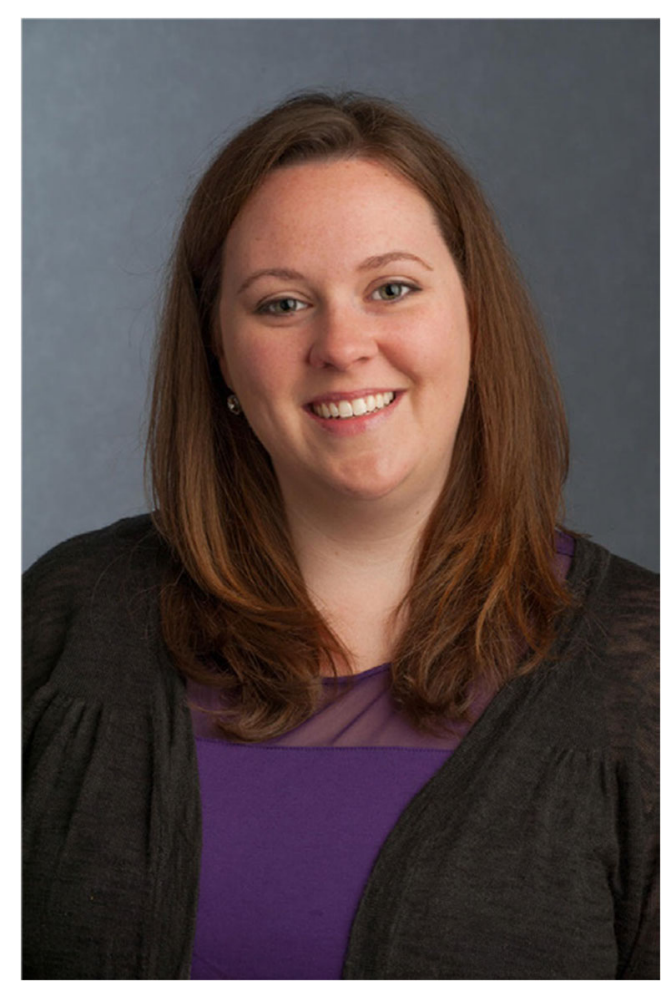

